\title{
Philosophy and Mediation. A Manifesto
}

\author{
Alessandro De Cesaris \\ ORCID: https://orcid.org/0000-0001-5221-5386 \\ (University or Naples “Federico II", alessandro.decesaris@gmail.com)
}

\section{Introduction}

While the relationship between philosophy and media has been vastly discussed by different traditions and in different contexts, the essential importance of this topic has often been neglected. The problem of "media" in philosophy, just like the existence of something like a "philosophy of media" is often relegated to the idea of a specific subdiscipline in the wider context of philosophy in general (see as an example Hassan \& Sutherland 2016; Konitzer 2006; Margreiter 2007). According to this view, "philosophy of media" is just another ramification of philosophy next to "philosophy of science" or "philosophy of art" and so on. More specifically, "philosophy of media" appears to be a sub-ramification of philosophy of technology (see Leidlmair 199911).

According to other views, the problem of the relationship between media and philosophy has a metaphilosophical nature, and addresses the means through which philosophy can be done, published and discussed today².

As these two dimensions often intertwine, they agree in viewing the relation between philosophy and media as something secondary, not essential for the sake of defining what philosophy is, and how it works.

The aim of this paper is to offer an opposite view, according to which the relation between philosophy and media, and more radically between philosophy and mediation, is essential in order to understand not only what philosophy has always been, but also and in particular what it is today and what it could become in the future.

The importance of media has become more and more evident in the present era, and our time requires a deep understanding of the nature of technology, of its potentialities

1 A deeper analysis of the problem of Media Philosophy can be found in Mersch (2003).

2 This issue is discussed in Marconi (2014). 
and risks. On the other hand, though, the reflection on media cannot be limited to a simple study of technology, but must be rather put in the broader context of the question concerning mediation in itself, a question that requires an answer articulated on many different levels (logical, anthropological and social at least).

The idea at the basis of this paper is that a proper philosophical understanding of the problem of media can illuminate the question concerning the identity of philosophy today, and suggest us a way to solve it. In order to prove this, a brief analysis of the present views on philosophy in the public debate will be required, as well as an attempt to show how the question concerning media is not at all new, but rather interests philosophy since from its beginning.

A key aspect of this analysis, however, is the clarification of the relationship between the question of media and the problem of mediation. As it will be clear, philosophy of media can be understood as a specific sub-genre of philosophy just because media themselves are interpreted as a certain kind of "object". In this way, philosophy of media should be that particular philosophical discipline that deals with documents, newspapers, television, digital devices or some other things, according to a view that understands "media" as "information media" or even "mass media" ${ }^{3}$. On the contrary, if we understand media as performative entities, whose essence is to be the substrate of a mediation process, it is immediately clear that the domain of media extends far beyond the are of communication technologies. This perspective also entails that if we understand media as "objects", as a certain kind of "things", we have already made it impossible to grasp their essence.

In this paper I will not expressly deal with the problem of media. I will rather try to explain how a deeper understanding of the relationship between philosophy and mediation can lead to a new way to theorize media, and to a notion of philosophy of media that is not only a sub-genre of philosophy of technology, but, rather, a general description of philosophy and of its task, today and in the past.

\subsection{Core theses of this paper.}

It will be useful to briefly summarize the main assumptions and theses I am going to illustrate and defend in the following pages, in order to clarify the argumentative structure of the whole paper.

Three substantial elements can be individuated: a general interpretation of the present state of affairs with regard to philosophy and its identity; a deeper analysis of the reasons and circumstances that generated this state of affairs; finally, a theoretical proposal concerning the way we can understand philosophy, with particular reference to the relevance of this understanding not only for the future of philosophy, but also for its past.

3 It will be useful to specify that the notion of "media" accepted in this essay is very close to the one proposed by Marshall McLuhan (see McLuhan 1964). According to this view "media" are technological extensions of man, of his body and of his organs. However, in a broader sense "media" are also all those elements whose essence is to be the substrate for mediation. 
Firstly, I am going to argue that some paradoxical elements can be recognized in our present cultural landscape with regard to the status of philosophy. There are some contradictory assumptions about philosophy, both in the public sphere and in the scientific debate. This fact makes it difficult to think about philosophical practices as a unity.

Secondly, I am going to suggest the idea that this fragmentation is the result of a substantial misunderstanding about the nature, the aims and the methods of traditional philosophy. The future of philosophy depends on our ability to rethink it in continuity with our tradition.

Finally, and with a very close relation to the previous point, today it is possible to reinterpretate the goal and the method of philosophy in the form of a «speculative mediology»4. This would allow us to avoid any rupture with our philosophical tradition, but at the same time to model our practices on the basis of our present needs.

\subsection{Why a Manifesto.}

It is also appropriate to clarify the subtitle of this paper, and thus explain why I have conceived it in the form of a manifesto. Of course, the idea of a manifesto emphasizes a direct reference to the present, to the current debate and public discourse (as in Badiou $2008,7)$. It will be evident that this reference does not rule out historical remarks. On the contrary, a historical assessment of the assumption at the core of this paper and of the analyses it proposes will be essential.

As a manifesto, this paper has primarily a practical and programmatic aim. While it offers an interpretation of philosophy, an analysis of its condition and of its possibilities, this descriptive pursuit aims at suggesting something philosophers can - and in a certain way should - do about their own discipline. Here "practical" is not understood in contraposition to "theoretical", but rather in complete unity with it. The aim of this paper is to suggest a way philosophers could reshape and rethink their own theoretical practices in the context of our actual social, political and technological setting.

This also means that this paper has an inherently metaphilosophical nature. It is, first of, a philosophical paper about philosophy. And yet, and this will be clear in the exposition, I agree with the thesis that a peculiar aspect of philosophy is the impossibility to distinguish between metaphilosophical and philosophical level. This means that, by addressing a metaphilosophical theme, I will also defend some philosophical theses.

Finally, this paper is conceived as a manifesto because its aim is to provide some groundwork for the foundation of a philosophical discipline, whose name is still to be found, but that could call itself "mediology", or "philosophy of mediation", or "media

4 The expression "mediology" is used here with no particular reference to the work of Régis Debray (see for instance Debray 1999). The work by Debray is of great interest for the perspective depicted in this paper, since it aims at describing "mediology" as a discipline that does not limit the analysis to modern media. And yet, in Debray's work mediology still does not get to the level of a "general theory of mediation", as I will try to argue in the next pages. 
philosophy". As it will become clear, though, this philosophical discipline does not aim at defining itself as a philosophical investigation directed towards a specific object, but is rather conceived as a new understanding of philosophy as a whole, or even better as a new form of "first philosophy" in Aristotelian sense.

\section{Some Antinomical Views about Philosophy Today.}

I will start by showing some paradoxes in the way the role and the meaning of philosophy is discussed today. The reason for which I will point out the contradictions in the public discourse is not that I would like to prove that the current opinions about philosophy are wrong.

On the contrary, I will argue that they have a certain significance in order to understand the situation of philosophy today, and that those contradictions, far from being the result of a mistake, instead point out some critical aspects of the matter. In order to do so, it will be necessary to take into account both the common understanding of philosophy in the public sphere, and the way philosophers and experts understand their own discipline.

The use of the word "antinomy" want to emphasize a specific character of the present cultural setting: the presence of opposite views about philosophy is not simply the sign of the existence of some sort of disagreement, something that could be interpreted as a positive and healthy element of the debate. I will rather try to show how these opposite views are often present at the same time, latently active as a sort of shared and unreflexively accepted persuasions concerning the status of knowledge, the role of intellectuals in the society, the signficance of the question concerning truth and the relationship between thought and reality.

I will use these four elements to suggest an analytical scheme made of four different antinomies. These antinomies are not meant, of course, to be exhaustive in order to present the actual debate concerning philosophy. Their function is just to illuminate some problematic aspects in the way philosophy understands itself, and in the way it is viewed in the public sphere.

\subsection{Philosophy and other disciplines.}

The first antinomy concerns the relationship between philosophy and other sciences. The epistemological status of philosophy is often questioned, but today the main problem is the way philosophy interacts with other forms of knowledge. The antinomy could be formulated as follows:

Thesis. Philosophy must be interdisciplinary. "Pure" philosophy is not useful nor relevant today, and philosophers must work together with scientists, artists, writers, researchers in other human sciences (Lucci 2018). 
Antithesis. Today many particular sciences have obtained an independent epistemological status, and their object needs to be dealt with through specific methods and research procedures. Philosophers who deal with the objects of other disciplines are just amateurs (Friedland 2012).

The confusion concerning the meaning of philosophical knowledge leads to contradictory conclusions: on one side, philosophy needs to interact with other sciences in order to obtain epistemological relevance; on the other side, though, philosophy can't really offer any significant contribution to what other sciences do, since they are indeed independent and autonomous, and do not need the intervention of philosophy in order to deal with their object.

This issue is connected with another shared persuasion about the notion of "encyclopaedia". It is commonly agreed that philosophy must not be encyclopedic. The idea of an encyclopedia of philosophical thought is outdated, and reminds of an obsolete, dogmatic and metaphysical past ${ }^{5}$.

\subsection{Philosophy and society.}

While the first antinomy addressed the relationship between philosophers and other scientists, the second antinomy addresses the relationship between philosophy and society, specifically the social status and task of the philosopher.

Today the philosopher is essentially a professor of philosophy or, in fewer cases, an independent essayist. In the view of the broad public the philosopher is basically a writer, even though it is not quite clear whether he's more similar to a scientist or to a novelist. This confusion is not directly the object of the antinomy, but leads to it: the problem is in fact the way philosophy should be done, if it is more of a scientific - enclosed - quest for knowledge, or rather a public intellectual practice, whose essence is the relationship with the "public".

Thesis. Philosophy must abandon its ivory tower and "speak to the people". Philosophers cannot just discuss with one another, they have to address people and produce a knowledge that is accessible to all?.

Antithesis. Philosophy should not be for everyone-just like hard science. Unfortunately, today philosophers are just media personalities, whose work is hardly distinguishable from journalism. Their theories are not properly "science", but are rather slogans created in order to charm the public (Marconi 2014).

5 The notion of "encyclopaedia" is object of a well-known critical analysis in Foucault (1989).

6 Here the double meaning of the word "public" must be kept in mind. On one side, public is what regards the public sphere. On the other side, the public is the crowd of spectators-buyers.

7 The metaphor of the ivory tower is expressly mentioned in Huenemanniac (2014).

8 In Marconi's book this description fits the stereotype of the "continental" philosopher. 
On one side, philosophy is connected to the aristocratic idea of a closed élite of intellectuals, whose theoretical problems are unintelligible and whose language is voluntarily obscure. On the other side, the public dimension of philosophy is used as a proof of its inconsistency as a science. The antithesis leads to the idea that anyone can do philosophy, since there is no "philosophical method" per se that distinguishes the arguments of a philosopher from the ones that result from informed common sense.

\subsection{Philosophy and truth.}

The third antinomy addresses the object of philosophy and its aim. The idea that philosophy has lost its connection with truth is quite widespread, in the public opinion as well as among the philosophers. Philosophy ultimately deals with questions "about" truth, concerning its meaning and significance, but the task to "find" truth has ultimately been passed to particular sciences, in particular to the empirical ones. We can formulate the antinomy as follows:

Thesis. Philosophy must avoid any claim to "truth". It must be "open" and not "closed", and the paradigm of hard truth is ultimately intolerant and dogmatic ${ }^{9}$. Philosophy does not need such a paradigm in order to be a proper science.

Antithesis. Philosophers are just very well read opinionists. Philosophy never proved anything, and there is constant struggle and disagreement about any philosophical topic ${ }^{10}$. Therefore, philosophy has no actual grasp on truth, and it is not a science.

On the one hand, the separation between philosophy and truth is not the object of a descriptive analysis, but rather a normative idea. It is not that philosophy does not aim at finding truth anymore: it should not. On the other hand, though, the lack of "hard" philosophical truths that can be agreed upon in a definitive way is the reason - since from the antiquity - for a certain suspect against philosophers. The antithesis of this third antinomy seems to be identical to the one of the second antinomy, but there is an essential difference: in the second antinomy, the suspect against philosophy arises from its presence in the media. Here, the suspect is grounded in the way philosophy presents its own results, and in the way the philosophical debates evolved throughout the centuries.

\subsection{Philosophy and reality.}

The last antinomy deals with the relationship between philosophy and reality. The word "reality" here does not refer to some sort of "realism", but rather to the world of everyday experience, to what is intersubjectively and socially accepted as real. The

9 This is allegedly the claim of what Caputo called "radical hermeneutics" (Caputo 1987, in particular p. 209 and ff.).

10 This opinion is of course very common since the ancient times. As a recent example, connected to the public debate, see Pigliucci 2014. 
antinomy addresses not much the object and aim of philosophy, as the third, but the "field" of philosophy, its domain and place. We will formulate it in this way:

Thesis. Philosophy must be original. Its task is to create new perspectives, to show things from a different point of view, to create new concepts, to offer the model for a new (and different) possible reality ${ }^{11}$.

Antithesis. Philosophers live outside of the real world, they build castles in the air and their theories lack any real reference to reality. Philosophy never "tells it like

it is", which is ultimately done by hard sciences ${ }^{12}$.

On one side, philosophy evokes the idea of "original", independent thought. The philosopher is first of all a creative thinker, someone who managed to think like no one else before. On the other side, thought, philosophy is accused of being distant from common people's thought. This also means being distant from common people's problems and interests, and ultimately from the cultural and social universe shared by everyone.

Again, here the antinomy looks similar to the previous one. The difference is simple: the problem is not the "epistemic value" of philosophical statements, but rather the interest of their object for people. While scientific truths could seem to be abstract, but ultimately translate into technological progress and into understandable and interesting popularised description of nature and of the world, philosophy deals with topics that seem in no way connected with our life.

\section{A Rehabilitation of Systematic Philosophy}

This lack of certainty in the determination of philosophy's identity, of its task and object, as well as of its relationship to other disciplines and to the public, is the symptom of a crisis that has been long detected by philosophy itself. Today it is not granted that philosophy is necessary, useful or even licit.

I will try to point out that a rehabilitation of philosophy as a systematic enterprise could be a way out of this crisis, or that it could at least be a good attempt to identify philosophy and seriously discuss about its public function. On the basis of the analysis I have just offered, the only way to argue in favour of this idea is to show how a systematic understanding of philosophy can help to overcome the antinomies exposed in the previous section.

First of all, this will require a specific understanding of what "systematic means". Secondly, it will be necessary to show how such an idea can help solving the antinomies we pointed out. Finally, I will show why this idea of systematic philosophy has to be

11 A good expression of this approach is the work by Andreas Urs Sommer (2012a and 2012b; see also Hàjek 2014).

12 This opinion is also a classical one, already discussed in Plato's Theaetetus and then analysed by many scholars. See for instance Blumenberg (2015). 
linked to the core topic of this paper, namely the relationship between philosophy and mediation. In fact, I will argue that only thanks to a proper understanding of mediation as the domain of philosophy, it is possible to suggest an idea of systematic philosophy that won't be outdated or unrealistic in the present epistemological landscape.

\subsection{An Aristotelian argument.}

A curious paradox arises: our time, in which philosophy has become a profession funded with public money by governments, is also the time in which the public importance and meaning of philosophy has been questioned in the strongest way. It is not generally understood why governments should invest in philosophical research, and philosophers often avoid such questions by celebrating the "usefulness" of philosophy as its distinctive character. In this context, Aristotle's metaphilosophical argument for the necessity of philosophy seems to be outdated. The argument can be summarized as follows: «whether we must philosophize or not, it is necessary to philosophize. In fact, in order to prove that we must not philosophize, we have to» (Alex. Aphr., In Topica, 149, 9-17).

The problem with this argument is that it does not take into account the possibility to simply ignore the question concerning philosophy. The general premise of the argument is that people are interested in discussing about philosophy, something that could be given for granted in a society in which philosophy and "knowledge" in general were still basically identified. Today this identification is not possible anymore, and it is instead the scientific value of philosophy that is constantly questioned.

A significant proof of the outdatedness of this argument is the fact that its realisation does not determine the survival of philosophy, but rather its crisis. The present status of philosophy is a critical one precisely because it seems that philosophy only lives in the form of its own negation, like some sort of undead creature. Philosophy today is reduced by many to the proof that "we must not philosophize". Once this proof takes place, though, the result is not a new form of philosophy, but rather the end of philosophy and the subsequent abandon of the term "philosophy" itself (Lucci 2018; Groys 2012). And yet, despite its outdatedness, the Aristotelian argument is interesting because of its implicit premise: discussing philosophical topics requires the same argumentative instruments required for discussing about philosophy in general. That is to say, that philosophy and metaphilosophy are the same discipline.

Metaphilosophy is not different from philosophy because philosophy determines its own object just as it determines itself. The question concerning the object of philosophy can only be answered by considering the way philosophy itself is instituted. This picture is actually confirmed by the way Aristotle introduces the question of philosophical knowledge in the Book I of Metaphysics, but can be found in many classical attempts to justify philosophy and identify its specificity.

\subsection{Philosophy as a systematic enterprise.}


This position is interesting for us for two reasons. On one side, it allows to identify the reason of the crisis of philosophy. This crisis originates from the gap between the object of philosophical research and the self-consciousness of philosophy itself. Philosophy is in crisis because either it presupposes its object and its method, assuming it from its own history, or it does not reflect on the relationship between its object, its method and the way it understands itself.

On the other side, and as a direct consequence of the former point, this position allows arguing in favour of a systematic understanding of philosophy. We now need to specify what I mean with the word "systematic". A first approximation can be formulated as follows: philosophy is inherently systematic because it does not inherit any determinate object, nor method. Philosophy as a plastic activity shapes itself and requires constant interaction with its own time.

Any attempt to pre-determinate philosophy with regard to its object or method leads to a - less or more explicit - crisis. This means that philosophy is inherently metaphilosophical: the metaphilosophical debate about what philosophy cannot be viewed as something "secondary", but is rather a core element of philosophy itself ${ }^{13}$.

This kind of approach allows to overcome the antinomical statements about philosophy I have illustrated in section two. Let's see how:

First Antinomy. Philosophy is not interdisciplinary, but is encyclopaedic. This does not mean that philosophy is "knowledge of all things", but rather that its interaction with other disciplines always obeys to an autonomous epistemological project.

Second Antinomy. Philosophy is neither technical nor popular. There is no preestablished method, language or style for philosophy, since it used all methods, spoke through all kinds of media and used every possible style. Everybody can philosophize, but this does not mean that philosophy is simply common sense: on the contrary, it means that philosophy is an enterprise that requires a preparation, but that cannot be understood as the application of a knowledge, or of a method, to an object.

Third Antinomy. Philosophy is a praxis, not a collection of statements. Its object is not "truth" in the ordinary sense, since it does not aim at producing knowledge of any particular object. This idea of philosophy traces back to a time in which the difference between philosophy and other forms of knowledge was still blurry.

13 This account of the idea of "system" is very strongly inspired by classical German philosophy, in particular by the philosophy of Fichte and Hegel. A very important point that needs to be made is that the idea of a system is in no way connected to the need to "account for all knowledge" once and for all. On the contrary, both Fichte and Hegel viewed this kind of enterprise as structurally plastic and historically situated: a philosophical system is not something that can be done once and kept forever, it is an activity that must be constantly performed. In other words: a philosophical system is a spiritual act, not a spiritual fact. 
Fourth Antinomy. Philosophy is creative, but not in the sense that it aims at producing "original" knowledge. Every philosophical enterprise is creative since it is the effect of an act of absolute foundation that reflects upon its own premises and builds a knowledge that discusses its own status ${ }^{14}$.

Of course, this is still a negative approximation to the topic of this paper. A possible problem with this depiction of philosophy is that it leaves out the reference to a history of philosophy, and thus the possibility to connect many different philosophical enterprises between them and collect them under the same name of "philosophy". In other words, we could ask this question: if every philosophical pursuit is autonomous and obeys to its own rules, how do we recognize two completely different philosophies as "philosophies" nevertheless? Is this purely negative definition sufficient in order to determine the field and domain of philosophy throughout history?

What is now left to do is a positive determination of the nature of philosophy through the discussion of the relation between philosophy and mediation. The task is precisely to show how the focus on mediaton will allow at the same time a justification of this systematic understanding of philosophy, and the reconnection of philosophy to its history. Much more strongly, it will be only through some brief historical references that it will be possible to justify the idea of an essential connection between philosophy and mediation.

\section{Philosophy As Mediology.}

We have established a connection between encyclopaedia and mediation. In order to explain it, let's go back to the answer to the first antinomy, and let's specify in which sense philosophy is - or must be - encyclopaedic, and in which sense it isn't, or isn't anymore, or shouldn't in the future.

Two elements are usually connected with the idea of an encyclopaedic knowledge, which are not fit to describe the kind of knowledge pursued by philosophy. The first element is eternity: an encyclopaedia refers to a steady, definitive knowledge that can be considered part of heritage of a whole culture. In contraposition to this, philosophy pursues a plastic knowledge, something that cannot be thought once forever, but that we must constantly rethink.

The second element is the need for a steady articulation of topics and disciplines. An encyclopaedia is based on a structure, and aside from the contents of the knowledge, its own articulation is assumed to be definitive. On the contrary, and as we have already

14 This does not mean, of course, that every philosophy has to start from zero, as in the work by Descartes. On the contrary, each philosopher must choose to organize and discuss the material available for him. The point is precisely how he chooses to do so, and in this landscape, Descartes' approach is only one among many. 
remarked, philosophy constantly reshapes its own articulation and the idea of knowledge itself.

It is easy to show that these two elements obey to a very narrow and specific idea of encyclopaedia, and that such an idea always represented quite the opposite: an intellectual activity that organised the knowledge of a certain era in a comprehensive system.

This is exactly how philosophy is encyclopaedic, and yet its activity cannot be reduced to this, because otherwise it would be only some kind of meta-science. In other terms, what must the philosopher know? What is the object of philosophy, if it is not only - and not in the first place - a meta-reflection on knowledge?

The answer I would like to propose is that the object of philosophy is mediation, and that philosophy can be described in the broadest sense as the "science of mediation". As far as knowledge, politics, ethics, logic, nature, metaphysics, love and so on are at the same time forms of mediation, or require the theorisation of specific forms of mediation, then is philosophy also a theory of knowledge, of politics, of nature and so on ${ }^{15}$.

The key aspect of this point of view, and therefore the first element necessary in order to grasp the meaning of mediation, is that philosophy does not deal with "things", but rather with the way things are dynamically interconnected. Philosophy basically shows that what appears to be separated (sacer) is united, but not in a static way. Philosophy is the theory of mediation, not just the theory of relation. It does not only show that and how things are connected, but it tries to think how they pass into each other, how they interact.

This means that philosophy is not science of united things, but science of the unity of things. The main object of philosophy are the various forms of limit and boundary (determination). Philosophy is the theory that shows the necessity of determination, but also the necessity for every determination to be overcome, ov every distinction to be unified. Mediation is precisely this tension, the compresence of limit and passing through, the necessary unity of determination and dissolution, of identity and otherness ${ }^{16}$.

If this is true, then philosophy is systematic for two reasons. The first is that the idea of mediation as essential dimension of philosophy is valid on both the philosophical and meta-philosophical level, and the two levels are deeply interconnected. Mediation is not the object of any particular science, it is rather a "philosophical object", meaning that it is the product of an act of creative intellectual reflection. We can describe philosophy as the theory of mediation only insofar we theorize mediation as a philosophical object ${ }^{17}$.

15 What I mean by this is not that love, knowledge, politics and so on can be understood only as specific forms of mediation. On the contrary, for example, it is possible to think love as an object, but that is not a philosophical understanding of love (this is precisely the point made by Plato in his Phaedrus).

16 Many ways have been found throughout the whole history of philosophy in order to express this idea. It is not an aim of this paper to select one of them. The point is precisely the opposite: each philosophy is a different way to autonomously theorize the problem of mediation.

17 By this I mean that "mediation" is not immediately a "thing", there is no way to describe mediation as a specific domain of objects. Also, any further distinction between "metaphysical" and "epistemological" understandings of mediation cannot be presupposed, such distinctions can only be the product of the way mediation itself is theorized in the context of a specific philosophical 
The second reason is that, by doing so, a comprehensive meditation concerning many different particular objects is required. These objects are dealt with by specific sciences, and yet, by theorising the kind of mediation they show, incarnate or require in order to function as they do, philosophy does not invade the territory of other disciplines, but does not ignore them either.

\subsection{Mediology and history of philosophy.}

This attempt to determine the identity of philosophy respects the answer to the fourth antinomy: while it tries to provide an answer based on a creative act of intellectual elaboration, it does not attempt to say anything original about philosophy. On the contrary, the main argument in favour of the truth of this attempt is precisely the fact that it allows a retrospective reinterpretation of philosophical tradition.

It is not by chance that the two distinctive objects of philosophy according to the Greeks, Being and Universality, are essentially forms of mediation. Without pushing the analysis in depth, "being" is the way ancient philosophy radicalizes the question concerning the first principle, that is the "arché". And yet, being is first of all the copula, the element that mediates between all things. Philosophy is the science of being qua being because it is the science of the mediation between all things ${ }^{18}$.

In the same way, philosophy creates the notion of "universal", but at the same time introduces the problem of the relationship between universal and particular. If we understand "universality" as a determination of some kind of thing, that we must theorize the kind of relationship between two orders of things, the particulars and the universals. On the contrary, universality has always been theorized as a mediation: universals are not "things", but rather what allows to logically pass from one thing to another.

The ancient connection between philosophy and dialectic is thus an essential element: philosophy is science of the "dia", science of the metaxy. Philosophy is mediology in a deeper sense than media philosophy. There can be a "philosophy of media" only because there is a philosophy of mediation. Philosophy as mediology is the theory of mediation, that is the theory of the many forms of passage from one determination to another.

\subsection{The philosopher is a pirate.}

This means that philosophy is a theory of the determination of things only insofar it shows how this determination does not close things, but rather opens them and allows describing their movement and changing. Every limit ( $\pi \varepsilon ́ \rho \alpha \varsigma)$ is also a passage through

enterprise.

18 Here a reference to Heraclitus (DK22B41) is necessary. According to this fragment, wisdom

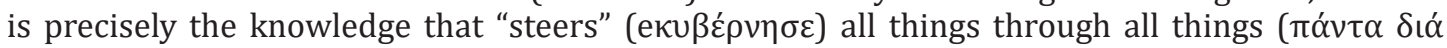
$\pi \alpha ́ v \tau \omega v)$. 
$(\pi \varepsilon \dot{\varepsilon} \alpha \sigma \iota \varsigma)^{19}$. The indoeuropean root *-per is of particular importance for the birth of philosophical language: it expresses the "through" (lat. per), the passage from something

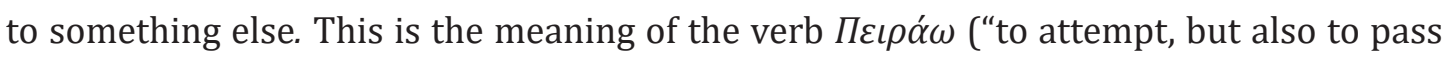
through"), but also of the verb $\pi \varepsilon i \rho \omega$, that is the act to pierce using the $\pi \varepsilon \iota \rho \alpha$, the extremity of the spear that runs through the body. From this root derive the Latin Periculum, but also the word experiential (Greek: $\left.\varepsilon \dot{\mu} \mu \varepsilon \iota \iota^{\prime} \bar{\alpha}\right)^{20}$. In the German language this correlation between experience and danger is conserved, since the word "Erfahrung" and the word "Gefahr" keep the reference to the verb "fahren", that is "to travel, to go from somewhere to somewhere".

In the same way, in Greek the word Пó $о$ ऽ (path, way) comes from the same root

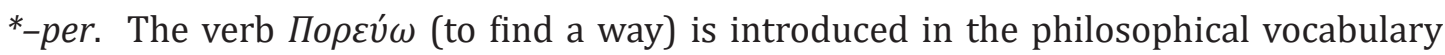
thanks to the word 'Aторí $\alpha$ (absence of a way through). A problem is literally something that gets in the way and prevents from going through, just as Wittgenstein will write in his Philosophical Investigations: «A philosophical problem has the form "I don't know my way about"» (Wittgenstein 2009, §123).

As we see, the reference to the -per, to the "through", animates both the philosophical lexicon and the image of the philosopher. This double significance of the reference to the through, philosophical and meta-philosophical, is also connected to an ethical stance towards the world. That of the philosopher is a particular ethos, and at the core of his attitude we find the idea of border-crossing. The philosopher is the one who recognizes limits and borders (the determination of things), but that in doing so at the same time encompasses them, because he knows that those borders are not absolute; that the very idea of a border requires the mind to cross it.

The one who crosses every border, who attempts to find a way through, is the $\pi \varepsilon \iota \rho \theta \dot{\eta} \varsigma$, literally the pirate. The existence of the philosopher is essentially connected to the idea of risk. According to Hegel the philosopher is «the individuality that risks itself in life (sich im Leben wagt)» (Hegel 1970, II, 14).

The paradigm of philosophy as a form of friendship, or love, (forms of mediation!) must be integrated with the other paradigm: the philosopher is "the enemy of all" (see Heller-Roazen 2009). At the same time, the idea of the philosopher as a quiet individuality has too often been confused with the idea of an existence free from any risk.

19 This is also true in the case of those philosophers, like Emanuele Severino, who deny the traditional understanding of change and becoming.

20 The reference to this word is already essential in Heraclitus, for instance in the fragment B1,

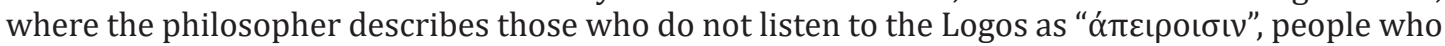

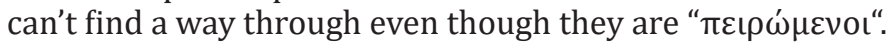




\section{Conclusion}

The aim of this paper was to show an essential connection between philosophy and mediation. Specifically, the objective was to define mediation as the object of philosophy, and to point out how a definition of philosophy as "science of mediation" is at the same time a valid reinterpretation of philosophical tradition and a possible suggestion about how we should think about the philosophical pursuit today.

This meditation about the task and the object of philosophy is particularly important in today's cultural landscape, in which the reflection on media and on technology seems to be one of the focuses - if not the focus - of humanities. Yet, if philosophy has widely engaged the topic concerning media and technology, it is still unclear what the specific contribution of this discipline to the field of media studies is. The expression "media philosophy" or "philosophy of media" is still used very vaguely, without any agreement about its meaning or about the identity of such a discipline.

My point is precisely that an effort to determine the identity of philosophy of media today can help in the task to re-identify philosophy at all. If we understand how philosophy can contribute to the debate about media and technology, we will also understand how philosophy can understand itself today, and find a way out of the antinomies that structure the common view about philosophy in our age.

\section{Literature}

Badiou A. 2008. Manifesto per la filosofia (with two prefaces for the Italian public).

Naples: Cronopio.

Blumenberg H. 2015, The Laughter of the Thracian Woman. A Protohistory of Theory. London: Bloomsbury.

Caputo J. D. 1987. Radical Hermeneutics. Indianapolis: Indiana University Press.

Debray R. 1999. Media Manifestos. On the Technological Transmission of Cultural Forms. London: Verso.

Foucault M. 1989. The Order of Things. London - New York: Routledge.

Friedland J. 2012. "Philosophy Is Not a Science", https://opinionator.blogs.nytimes. com/2012/04/05/philosophy-is-not-a-science/ (last visited 31.10.2018).

Groys B. 2012. Introduction to Antiphilosophy. London: Verso.

Hàjek A. 2014. "Philosophical Heuristics and Philosophical Creativity", in S. P. Elliott \& B. K. Scott (Eds.), The Philosophy of Creativity: New Essays. Oxford: Oxford University Press.

Hassan R. \& Sutherland Th. 2016. The Philosophy of Media. London: Routledge.

Hegel G. W. F. 1970. Werke in 20 Bänden. Frankfurt am Main: Suhrkamp. 
Heller-Roazen D. 2009. The Enemy of All. Piracy and the Law of Nations. New York: Zone Books.

Huenemanniac Ch. 2014. "Where Academic Philosophy Went Wrong." https:// huenemanniac.com/2014/08/19/where-academic-philosophy-went-wrong/ (accessed on October 31, 2018).

Konitzer W. 2006. Medienphilosophie. München: Fink.

Leidlmar K. 1999. "From the Philosophy of Technology to a Theory of Media." Philosophy and Technology 4(3):271-280.

Lucci A. 2018. "La filosofia si sporca le mani." https://www.doppiozero.com/materiali/ la-filosofia-si-sporca-le-mani (accessec on October 31, 2018).

Marconi D. 2014. Il mestiere di pensare. Torino: Einaudi.

Margreiter R. 2007. Medienphilosophie. Eine Einführung. Berlin: Parerga.

McLuhan M. 1964. Understanding Media. The Extension of Man. New York: McGraw-Hill.

Mersch D. 2003. “Technikapriori und Begründungsdefizit. Medienphilosophie zwischen uneingelöstem Anspruch und theoretischer Neufundierung." Philosophische Rundschau 50(3):193-219.

Pigliucci M. 2014. "Neil deGrasse Tyson and the Value of Philosophy." https:// scientiasalon.wordpress.com/2014/05/12/neil-degrasse-tyson-and-the-value-ofphilosophy/ (accessed on October 31, 2018).

Sommer U. A. 2012a. "Philosophie als Wagnis." Nietzsche-Forschung 20(1):19-28.

Sommer U. A. 2012b. Lexikon der imaginären philosophischen Werke. Berlin: Die Andere Bibliothek.

Wittgenstein L. 2009. Philosophical Investigations. London: Wiley-Blackwell. 
Alessandro De Cesaris (Naples)

\title{
Philosophy and Mediation. A Manifesto
}

\begin{abstract}
The current condition of philosophy as a discipline is quite problematic, in particular if we consider its relationship to other human sciences and to other disciplines in general. The philosophical debate appears fragmented, and philosophy itself has lost any specific role in the present scientific landscape. This situation determines a sort of "identity crisis", whose main consequence is the coexistence of antinomical views about philosophy in the contemporary scientific and public discourse.

Starting from this context, the paper aims at providing a description of philosophy as "theory of mediation". This description does not want to be 'original', but rather tries to emphasize an element that is always been rooted in the very essence of philosophy, but that has also often been neglected. Philosophy has always pointed out the necessity to think the in-between of things, their relation and the passage from one to another, rather than just offering a taxonomy or a factual description of the world. In order to prove this point, the paper offers an analysis of some classical texts, in particular of some fragments by Heraclitus and of a passage taken from Hegel's early writings.

A view that rethinks philosophy as "mediology" allows a rehabilitation of philosophy as a specific discipline and as a systematic enterprise, at the same time providing a new framework for the understanding of the relationship between philosophy and other sciences.
\end{abstract}

Keywords: metaphilosophy; media theory; mediation; encyclopaedia; philosophy.

Ethics in Progress (ISSN 2084-9257). Vol. 10 (2019). No. 1, Art. \#6, pp. 67-82.

Creative Commons BY-SA 4.0

Doi:10.14746/eip.2019.1.6 